University of Nebraska - Lincoln

DigitalCommons@University of Nebraska - Lincoln

Papers in Natural Resources

Natural Resources, School of

2007

Estimation of Catchment-Scale Evapotranspiration from Baseflow Recession Data: Numerical Model and Practical Application Results

Jozsef Szilagyi

University of Nebraska-Lincoln, jszilagyi1@unl.edu

Zoltan Gribovszki

University of Western Hungary

Peter Kalicz

University of Western Hungary

Follow this and additional works at: https://digitalcommons.unl.edu/natrespapers

Part of the Natural Resources and Conservation Commons, Natural Resources Management and Policy Commons, and the Other Environmental Sciences Commons

Szilagyi, Jozsef; Gribovszki, Zoltan; and Kalicz, Peter, "Estimation of Catchment-Scale Evapotranspiration from Baseflow Recession Data: Numerical Model and Practical Application Results" (2007). Papers in Natural Resources. 993.

https://digitalcommons.unl.edu/natrespapers/993

This Article is brought to you for free and open access by the Natural Resources, School of at DigitalCommons@University of Nebraska - Lincoln. It has been accepted for inclusion in Papers in Natural Resources by an authorized administrator of DigitalCommons@University of Nebraska - Lincoln. 
See discussions, stats, and author profiles for this publication at: https://www.researchgate.net/publication/222429897

\section{Estimation of catchment-scale evapotranspiration from baseflow recession data: Numerical model and practical application results}

Article in Journal of Hydrology · March 2007

DOI: 10.1016/j.jhydrol.2007.01.004

\section{CITATIONS}

58

3 authors:

Joe Szilagyi

Budapest University of Technology and Economics

104 PUBLICATIONS 1,847 CITATIONS

SEE PROFILE

Peter Kalicz

University of Sopron

103 PUBLICATIONS 368 CITATIONS

SEE PROFILE
READS

61

Zoltan Gribovszki

University of West Hungary, Sopron

53 PUBLICATIONS 383 CITATIONS

SEE PROFILE

Some of the authors of this publication are also working on these related projects:

Project The Complementary Relationship in Land Surface Evapotranspiration View project

Project Agrárklima.2: a national decision support system for forestry, rainfed agriculture and pasturelands in view of projected climate changes View project 


\title{
Estimation of catchment-scale evapotranspiration from baseflow recession data: Numerical model and practical application results is
}

\author{
Jozsef Szilagyi $^{\mathrm{a}, \mathrm{b}, *}$, Zoltan Gribovszki ${ }^{\mathrm{c}}$, Peter Kalicz ${ }^{\mathrm{c}}$ \\ a Department of Hydraulic and Water Resources Engineering, Budapest University of Technology and \\ Economics, 1111 Muegyetem Rkp. 3-9, Budapest, Hungary \\ b School of Natural Resources, University of Nebraska-Lincoln, Lincoln, NE, USA \\ c Institute of Geomatics and Civil Engineering, University of Western Hungary, Sopron, Hungary
}

Received 30 March 2006; received in revised form 23 December 2006; accepted 2 January 2007

\section{KEYWORDS}

Evapotranspiration;

Baseflow recession

\begin{abstract}
Summary By applying a nonlinear reservoir approach for groundwater drainage, catchment-scale evapotranspiration (ET) during flow recessions can be expressed with the help of the lumped version of the water balance equation for the catchment. The attractiveness of the approach is that ET, in theory, can be obtained by the sole use of observed flow values for which relatively abundant and long records are available. A 2D finite element numerical model of subsurface flow in the unsaturated and saturated zones, capable of simulating moisture removal by vegetation, was first successfully employed to verify the water balance approach under ideal conditions. Subsequent practical applications over four catchments with widely varying climatic conditions however showed large disparities in comparison with monthly ET estimates of Morton's WREVAP model.

(C) 2007 Elsevier B.V. All rights reserved.
\end{abstract}

\section{Introduction}

In watershed hydrology mean annual catchment-scale evapotranspiration (ET for short) can often times be estimated as the difference between long-term precipitation

\footnotetext{
A contribution of the University of Nebraska Agricultural Research Division, Lincoln, NE 68583, Journal Series Number 15169.

* Corresponding author. Address: School of Natural Resources, University of Nebraska-Lincoln, Lincoln, NE, USA.

E-mail address: jszilagyi1@unl.edu (J. Szilagyi).
}

the watershed receives and its ensuing runoff. A problem occurs when one is interested in ET rates over shorter periods, such as months, since then changes in water storage of the catchment cannot typically be neglected. ET is an important physical and biological indicator of energy and mass transfer rates as well as of photosynthetic activity of the vegetation cover of the catchment. As such, it greatly determines the level and temporal behavior of the watershed's runoff response to precipitation, consequently raising the possibility of back-calculating the typically unknown ET rates solely from measured runoff which may 
be of value in watersheds lacking meteorological observations.

The effect of ET on runoff recession has first been documented by e.g., Tschinkel (1963), Chow (1964), Crawford and Linsley (1966), Holtan and Lopez (1971), Singh and Stall (1971), and most prominently by Federer (1973). The latter author has clearly demonstrated for a 42-ha subcatchment (watershed \#3) of the Hubbard Brook Experimental Forest of New Hampshire (Fig. 1) that streamflow recession in the summer, during high transpiration activity, is much faster (i.e., having a steeper slope) than in early spring or late fall, when photosynthetic activity is yet or already absent.

While Tschinkel (1963) used the diurnal fluctuation of runoff to estimate riparian ET, it was Daniel (1976) who first employed the behavior of the recession limb of the hydrograph to deduce watershed-scale ET rates. Brutsaert (1982) a few years later outlined a brief generalization of Daniel (1976) method of a linear storage analogy by employing a nonlinear reservoir approach. This generalization, however, has not been methodically tested with measured and/or modeled data providing a rationale to the present work. Below the approach is described with some further modifications.

The simplified water balance of a catchment for an arbitrary time period of no precipitation can be written as

$\frac{\mathrm{d} S}{\mathrm{~d} t}=-(A \cdot E+Q)$

where $S\left[L^{3}\right]$ is the stored water volume over the watershed of drainage area $A\left[\mathrm{~L}^{2}\right]$, and $E\left[\mathrm{~L} \mathrm{~T}^{-1}\right]$ and $Q\left[\mathrm{~L}^{3} \mathrm{~T}^{-1}\right]$ are the evapotranspiration and streamflow rates (at the outlet of the catchment), respectively. As Brutsaert and Nieber (1977) demonstrated, drought flow rates (when ET is negligible) can, in theory, be uniquely related to the water volume stored in the saturated zone of the watershed, minimally affected by water resources developments
(McMahon and Finlayson, 2003). Recently Szilagyi (2003), with the help of numerical experiments, indicated that such a functional relationship can be maintained between recession flow rate and the water volume stored in the unsaturated and saturated zones combined. Recession flow of a catchment (again with negligible ET) therefore can be described by a nonlinear storage equation

$Q=a S^{b}$

where $a\left[\mathrm{~L}^{3(1-\mathrm{b})} \mathrm{T}^{-1}\right]$ (often called storage coefficient) and $b$ [-] are constant parameters, possibly changing values between early and late-time drainage of the catchment. Early-time drainage occurs when the effect of a finite aquifer length is not yet felt in the drainage rates, and late time, when it is.

Inserting Eq. (2) into Eq. (1) yields

$-\frac{\mathrm{d} Q}{\mathrm{~d} t}=a^{(1 / b)} b Q^{(b-1) / b}(Q+A \cdot E)$.

Eq. (3) transforms into

$-\frac{\mathrm{d} Q}{\mathrm{~d} t}=a^{1 / b} b Q^{(2 b-1) / b}=c Q^{d}$

provided ET is negligible with $c\left[\mathrm{~L}^{3(1-d)} \mathrm{T}^{d-2}\right]$ and $d[-]$ constants. Eq. (4) when plotted on a double-logarithmic coordinate system forms a straight line of slope $d$ and intercept value of $c$ (at $Q=1)$. Eq. (3), however, with a time-varying ET will form a cloud on a log-log graph, as demonstrated in Fig. 2 which contains the mean daily recession discharge (as the mean of the $(i-1)$ th and $i$ th values) plotted against its diurnal rate of change (as the difference of the $i$ th and $(i-1)$ th values) for watershed \#3 (1958-2004) within the Hubbard Brook Experimental Forest (Fig. 1). When ET is negligible, the points form the lower envelope (i.e., the densest part of the graph is scattered along a straight line) of the cloud since then for the same $Q$ a temporal change with

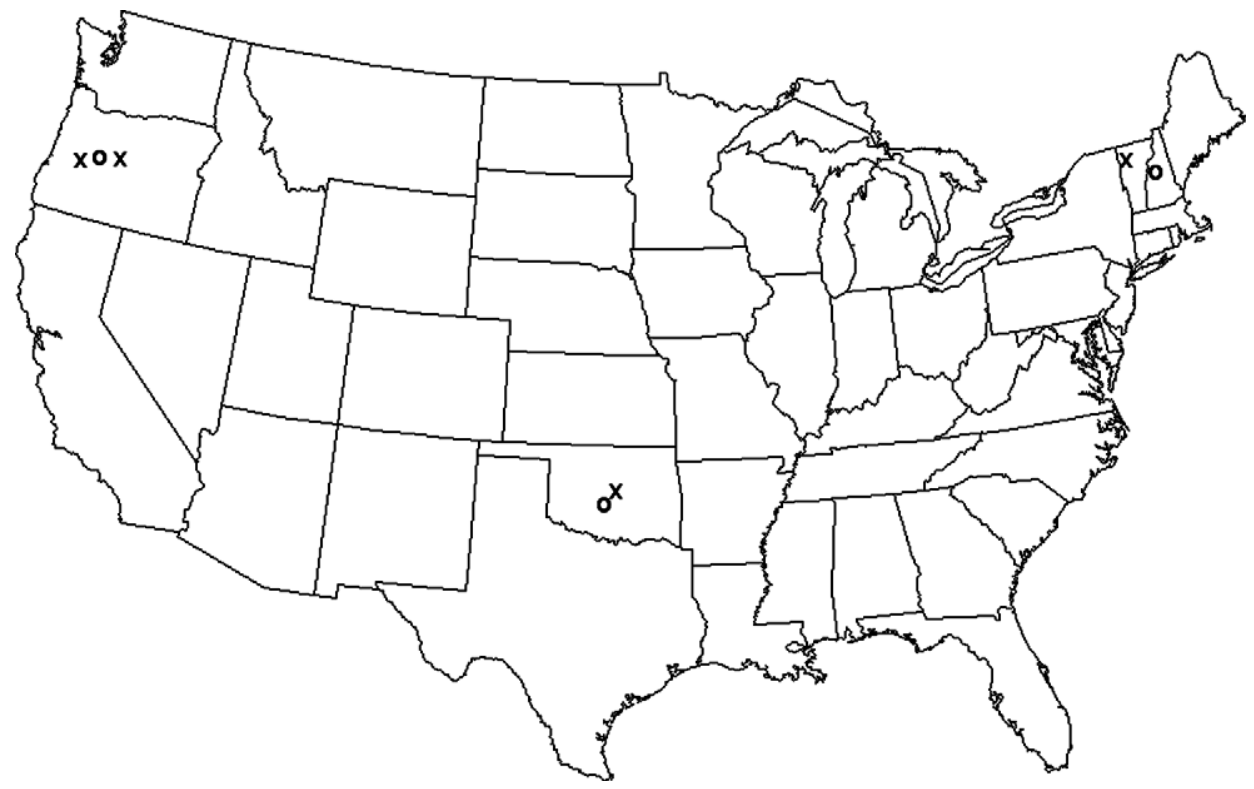

Figure 1 Approximate location of the study watersheds (o) and SAMSON sites ( $\mathrm{x}$ ). Watersheds (from west to east): Mack Creek $(\mathrm{OR})$, catchment \#5141 (OK), catchments \#3 and \#5 (NH), the latter two are shown at the same location on the map. SAMSON stations: Eugene (OR), Redmond (OR), Oklahoma City (OK), and Burlington (VT). 


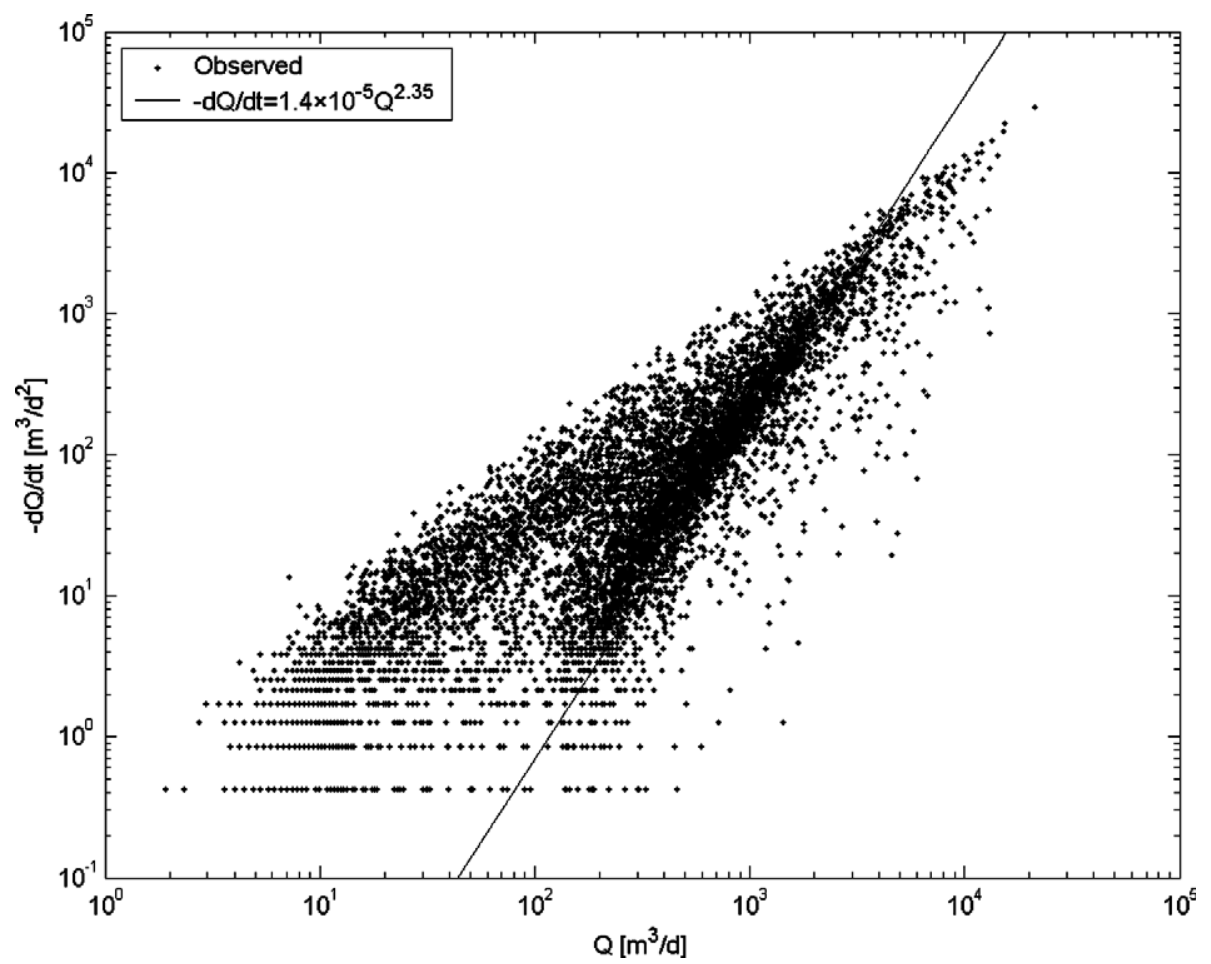

Figure 2 Recession-flow rate versus diurnal rate of change (1958-2004) for watershed \#3, Hubbard Brook Experimental Forest, New Hampshire, US. The straight line shown is the assumed limiting case of ET $=0$.

a smaller magnitude is expected from Eq. (3). By rearranging Eq. (3) an estimate for ET results as (Brutsaert, 1982)

$E=-\left(\frac{Q^{(1-b) / b}}{a^{1 / b} b} \frac{\mathrm{d} Q}{\mathrm{~d} t}+Q\right) A^{-1}$

A somewhat more practical form of estimating the ET rate can be obtained by subtracting Eq. (4) from Eq. (3) as

$E=\frac{\Delta\left(-\frac{\mathrm{d} Q}{\mathrm{~d} t}\right)}{A c Q^{d} / Q}=Q^{1-d}(\mathrm{cA})^{-1} \Delta\left(-\frac{\mathrm{d} Q}{\mathrm{~d} t}\right)$

where $\Delta($.$) now denotes the difference in the diurnal rate of$ change in runoff between what is actually observed (more precisely calculated from two consecutive mean daily values) for a given day and what the line of Eq. (4) yields, representing aquifer drainage with zero evapotranspiration. Both formulations, i.e., Eqs. (5) and (6), assume that the diurnal rate of change in runoff must be larger in amplitude, i.e., being above the line of Eq. (4), when ET is not negligible as when it is. Eq. (6) has the added advantage of explicitly relating ET to this observed deviation from the limiting, $\mathrm{ET}=0$, line. It also tells one that for a given difference in the diurnal rate of change between actual $(E T>0)$ and limiting $(E T=0)$ cases, ET is smaller when observed runoff is larger, provided $d>1$, and larger if $d<1$ (note that $d$ is always positive). In the linear aquifer case (i.e., $d=1$ ), ET is linearly related to this difference.

The theoretical line of $-\mathrm{d} Q / \mathrm{d} t=c Q^{d}$, however, is rarely the lower straight-line envelope in practice. The reason being that on any given day the stream may potentially be fed by small quantities of extra runoff (surface and/or subsurface) that are not substantial enough to reverse the trend of the recession flow, but significant enough to reduce the rate of change. Such extra contributions to the stream may stem from light rain (which is normally marked as 'trace' in the precipitation record), melting snow or even the cessation of photosynthetic activity and therefore, the shutting off the transpiration process due to the coloring of leaves in the fall (Federer, 1973), thus, letting the resulting surplus water (groundwater or soil moisture) normally taken up by the roots of the vegetation to seep to the stream. For the latter, an example is seen in Fig. 5 caused by changing ET rates during the day.

Another reason why the calculated change in the runoff rates may be below the theoretical line is due to the finite accuracy of runoff measurements. When the magnitude of the diurnal rate of change in runoff is around the order of measurement accuracy, the $-\mathrm{d} Q / \mathrm{d} t$ values typically line up along horizontal lines as is seen in Fig. 2. This issue will later be addressed, following the recommendations of Rupp and Selker (2006).

Before the above described method is tested with measured runoff data (potentially influenced with the above corrupting factors), a numerical study was conducted to see if the technique can give useful ET estimates under such controlled conditions that exist in a numerical experiment. A successful numerical test was set to be the prerequisite for additional data analysis and practical ET estimations.

\section{A numerical study to test the applicability of the ET estimation method}

A finite element, two-dimensional model was employed to numerically integrate the Richards equation in its extended form (Lam et al., 1987) that describes subsurface flow in both the unsaturated and saturated zones 
$\frac{\partial}{\partial x}\left[K(\Psi) \frac{\partial h}{\partial x}\right]+\frac{\partial}{\partial y}\left[K(\Psi) \frac{\partial h}{\partial y}\right]+s=m \gamma \frac{\partial h}{\partial t}$

where $K$ is the suction/pressure-dependent hydraulic conductivity $\left[\mathrm{L} \mathrm{T}^{-1}\right] ; h$ is the total hydraulic head $[\mathrm{L}] ; \Psi$ is the suction/pressure head $[L] ; s$ is a source/sink term $\left[\mathrm{T}^{-1}\right] ; m\left[\mathrm{~L} \mathrm{~T}^{2} \mathrm{M}^{-1}\right]$ is the slope of the water retention curve which becomes the coefficient of volume change in the saturated zone; $\gamma\left[\mathrm{M} \mathrm{T}^{-2} \mathrm{~L}^{-2}\right]$ is the unit weight of water; and $x$ $[\mathrm{L}], y[\mathrm{~L}]$, and $t[\mathrm{~T}]$ denote the horizontal, vertical and temporal coordinates, respectively.

The horizontal, rectangular-shaped aquifer (Fig. 3) of unit length and a width of $20 \mathrm{~m}$ was drained by a fully penetrating stream by dropping the water level of the stream

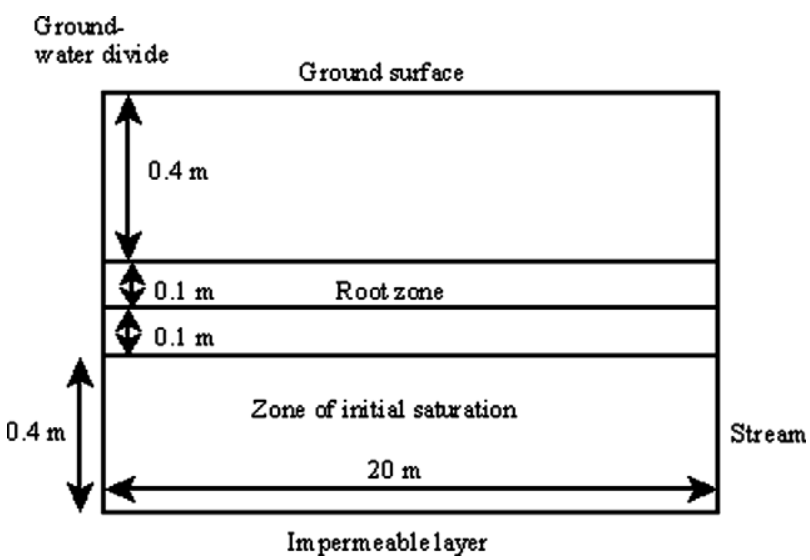

Figure 3 Schematic cross-section of the aquifer employed in the numerical study of aquifer drainage. instantaneously from an initial $h_{0}(=0.4 \mathrm{~m})$ value, the height of the horizontal groundwater-table at $t=0$ in the aquifer, to $0 \mathrm{~m}$. The aquifer was supposed to be made up of sand the hydraulic properties of which described in detail by Szilagyi (2003). Drainage was conducted under three different conditions: (a) ET was set equal to zero throughout the drainage period of 6 days; (b) ET was set to be constant $\left(=0.1 \mathrm{~m}^{3} \mathrm{~d}^{-1}\right.$ or $\left.5 \mathrm{~mm} \mathrm{~d}^{-1}\right)$, and; (c) ET $\left(E_{\mathrm{m}}\right)$ changed throughout the day

$$
\begin{aligned}
& E_{\mathrm{m}}(t)=A \sin ^{2}\left(\frac{t}{3.82}\right), \quad 0 \leqslant \bmod (t / 24)<12 \\
& E_{\mathrm{m}}(t)=0, \quad 12 \leqslant \bmod (t / 24)<24
\end{aligned}
$$

where an $A\left[\mathrm{~L}^{3} \mathrm{~T}^{-1}\right]$ value of $8.35 \times 10^{-3} \mathrm{~m}^{3} \mathrm{~h}^{-1}$ assured that the daily ET total (i.e., the integral of Eq. (8)) equaled the constant ET case value of $0.1 \mathrm{~m}^{3}$. The 'mod' in the equation stands for the modulus of division, and $t$ is measured in hours. Eq. (8) was meant to replicate the daily rhythm of ET: not negligible values during one half of the day and close to zero during the other. The water fluxes described by Eq. (8) were represented through the source/sink term, s, in Eq. (7) for the $10 \mathrm{~cm}$ thick root zone of the aquifer (Fig. 3) in cases (b) and (c).

Fig. 4 depicts drainage of the model aquifer for cases (a) and (b). The steeper part of the graph corresponds to earlytime drainage (observable in the first day only), while the lower part represents late-time dewatering. The best-fit line overlain the late-time drainage values of case (a) (i.e., no ET) has a slope of $d=1.2$ and intercept $c=5 \times$ $10^{-5} \mathrm{~m}^{-.6} \mathrm{~s}^{-.8}$. The curve fitted over the values influenced by ET is a fourth-order polynomial for the logarithms of the $Q$ and $-\mathrm{d} Q / \mathrm{d} t$ values. The constant ET rate was

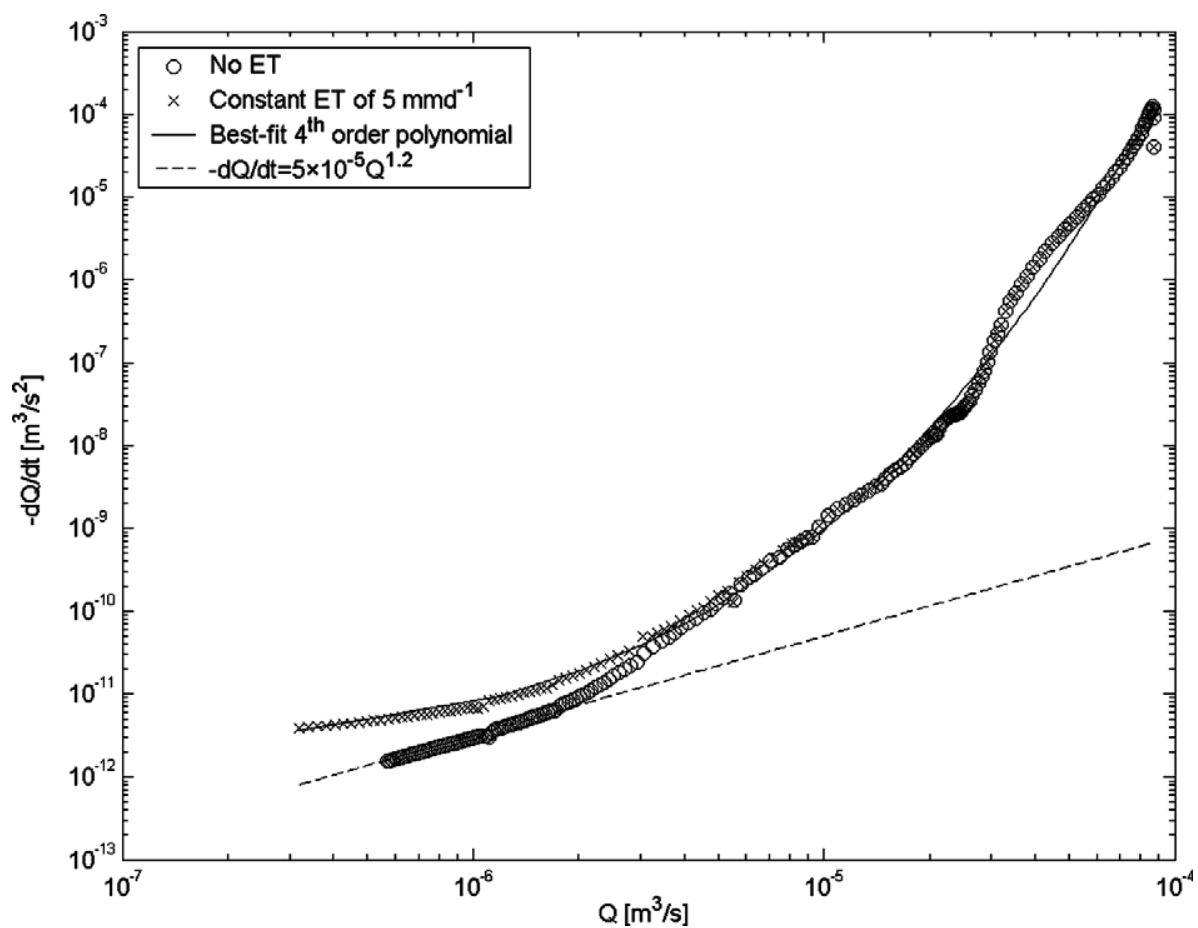

Figure 4 Double-logarithmic graph of the modeled rate of change in the groundwater discharge versus groundwater discharge values. The straight line is the best-fit line to the late-time drainage values (i.e., their logarithms) in the absence of ET while the curve is the best-fit fourth-order polynomial to the logarithms of the drainage values influenced by a constant $5 \mathrm{~mm} \mathrm{~d}^{-1}$ ET rate. 
estimated at the smallest 30 discharge values of the limiting case (no ET) with the help of Eq. (6), using the difference between the $c Q^{d}$ value and the fourth-order polynomial's value, both evaluated with the 30 discharge values. The so-derived mean ET estimate became $5.42 \pm 0.59 \mathrm{~mm} \mathrm{~d}^{-1}$, which is $8 \%$ larger than the actual ET value of $5 \mathrm{~mm} \mathrm{~d}^{-1}$.

Fig. 5 displays cases (a) and (c) with a fourth-order polynomial fitted over the values influenced by changing ET rates as described by Eq. (8). The mean ET rate estimate (of the 30 values) now became $4.82 \pm 1.97 \mathrm{~mm} \mathrm{~d}^{-1}$, which means an underestimation by $4 \%$.

\section{Application of the ET estimation method with small watershed data}

Application of Eq. (6) for estimating daily ET rates were conducted for four small experimental watersheds in the US: catchments \#3 (drainage area of $0.42 \mathrm{~km}^{2}$ ) and \#5 $\left(0.22 \mathrm{~km}^{2}\right)$ within the Hubbard Brook Experimental Forest in New Hampshire; the Mack Creek catchment $\left(5.81 \mathrm{~km}^{2}\right)$ in the H.J. Andrews Experimental Forest in Oregon; and for watershed \#5141 (16.45 $\left.\mathrm{km}^{2}\right)$ in the Washita Experimental Watershed, Oklahoma.

Catchments \#3 and \#5 are forested watersheds in the White Mountains, at a mean elevation of about $600 \mathrm{~m}$, with slopes of $10-15^{\circ}$, and receiving about $1400 \mathrm{~mm}$ of precipitation annually. On watershed \#5 there was a complete clearcutting of the woods to a trunk diameter of $5 \mathrm{~cm}$ in the winter of 1983-1984 with the timber subsequently removed.

The Mack Creek catchment is a heavily forested watershed in the Cascade Range of the Rocky Mountains in
West-Central Oregon, having a mean elevation of $1000 \mathrm{~m}$ with average slopes of $10-15^{\circ}$, and receiving about $2300 \mathrm{~mm}$ precipitation a year.

Watershed \#5141 in Oklahoma is covered mainly by prairie grass interspersed with forests and croplands. The mean elevation is $400 \mathrm{~m}$ with slopes of $3-8 \%$ and mean annual precipitation of $730 \mathrm{~mm}$.

Fig. 2 displays the recession flow rate versus the diurnal rate of change for catchment \#3 in New Hampshire from the period of 1958-2004 with the assumed limiting case of zero evapotranspiration in the form of a straight line drawn by eyeballing as a lower envelope to the densest part of the cloud of data points. Fig. 6 displays the same data month by month. As expected, the points lie close to the limiting line of $-\mathrm{d} Q / \mathrm{d} t=1.4 \times 10^{-5} Q^{2.35}$ in the winter months, when ET is close to zero over the watershed. In April (and to a lesser degree in March as well) most of the data points lie under the limiting line due to the melting of snow, as was discussed above. As the vegetation greens up and ET increases, the points depart to the left from the limiting line, in accord with theory. By November, when most of the vegetation becomes dormant again, the points again start to line up over the limiting line.

Daily ET rates can be estimated by Eqs. (5) or (6) provided the corresponding magnitude of the $\mathrm{d} Q / \mathrm{d} t$ value is over the limiting line's value for the same $Q$. When mean monthly ET rates are desired, a problem arises since the method can yield estimates only for days with no precipitation and even then during recession flow periods only, provided the data point in the double-logarithmic graph is over the limiting line. A solution is that one calculates the mean

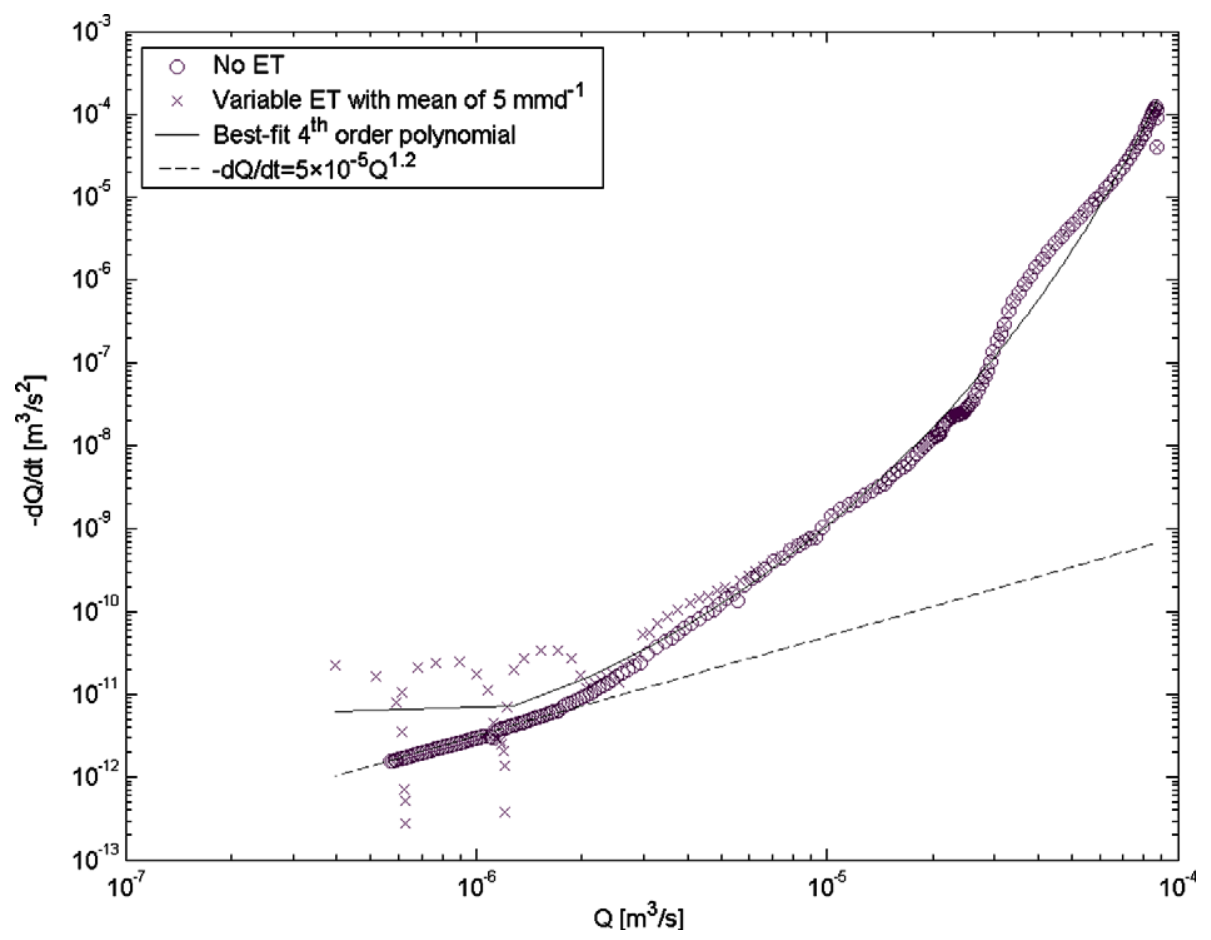

Figure 5 Double-logarithmic graph of the modeled rate of change in the groundwater discharge versus groundwater discharge values. The straight line is the best-fit line to the late-time drainage values (i.e., their logarithms) in the absence of ET while the curve is the best-fit fourth-order polynomial to the logarithms of the drainage values influenced by a variable ET rate of a mean value of $5 \mathrm{~mm} \mathrm{~d}^{-1}$. 

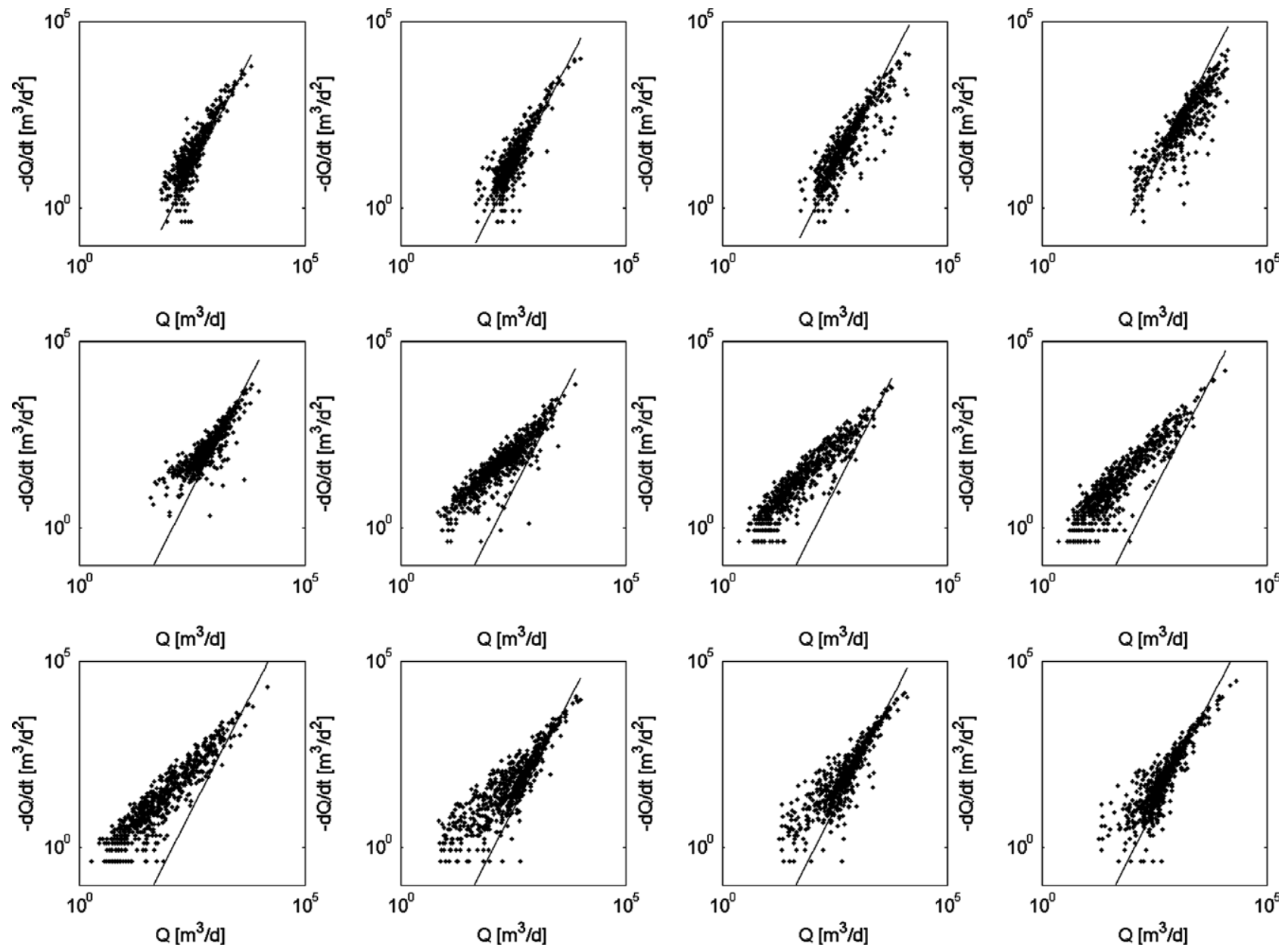

Figure 6 Recession-flow rate versus diurnal rate of change (1958-2004) by month for watershed \#3, Hubbard Brook Experimental Forest, New Hampshire, US. The months are row-continuous (i.e., first line of graphs is for January-April). The straight line is from Fig. 1.

daily ET rate from the available days for each month, and multiplies it with the average number of days with no precipitation in each month. This approach, therefore, assumes that ET is negligible during days with precipitation, and that in days when the data point is under the limiting line, ET is the same average rate that has been calculated. Note, that it can be performed only when one has information of at least the average number of days with precipitation for each month. The present ET estimation was aided by the availability of daily precipitation data for each watershed. Table 1 lists the estimated mean monthly ET rates for each watershed studied. From Table 1, mean annual ET of watershed \#3 in New Hampshire comes out to $561 \mathrm{~mm}$. This is about a $13 \%$ overestimation of the long-term (for the same period) difference in daily precipitation and runoff sums of $494 \mathrm{~mm}$.

Table 1 Mean monthly ET $(\mathrm{mm})$ estimates (rounded to nearest integer) for the watersheds studied

\begin{tabular}{|c|c|c|c|c|c|c|c|c|c|c|c|c|c|c|c|}
\hline & J & $\mathrm{F}$ & $M$ & A & $M$ & $\mathrm{~J}$ & $\mathrm{~J}$ & A & $S$ & 0 & $\mathrm{~N}$ & D & $E_{\text {est }}$ & $\left(E_{\mathrm{m}}\right)$ & Error (\%) \\
\hline \#3 & 19 & 16 & 11 & 4 & 28 & 97 & 95 & 93 & 100 & 54 & 25 & 19 & 561 & 494 & +13 \\
\hline * & 21 & 18 & 12 & 4 & 26 & 84 & 89 & 95 & 105 & 52 & 24 & 20 & 550 & & +10 \\
\hline$\# 5(U)$ & 14 & 13 & 8 & 4 & 23 & 89 & 119 & 132 & 124 & 48 & 18 & 14 & 606 & 500 & +21 \\
\hline$(\mathrm{L})$ & 24 & 23 & 16 & 12 & 44 & 136 & 148 & 146 & 160 & 77 & 36 & 27 & 849 & & +70 \\
\hline Mack & 28 & 26 & 17 & 13 & 24 & 40 & 30 & 43 & 80 & 102 & 71 & 36 & 510 & 439 & +16 \\
\hline \#5141 & 33 & 24 & 53 & 56 & 81 & 64 & 45 & 37 & 60 & 44 & 109 & 42 & 648 & 655 & -1 \\
\hline
\end{tabular}

ET for catchment \#3 was calculated by simple diurnal increments and also by employing the corrections (starred values) of Rupp and Selker (2006). The rest of the watersheds use such a correction. For catchment \#5 two limiting lines were drawn, an upper (U) and a lower (L) one, yielding widely differing ET estimates. $E_{\text {est }}\left(\mathrm{mm} \mathrm{yr}^{-1}\right)$ is the sum of the monthly values, $E_{\mathrm{m}}\left(\mathrm{mm} \mathrm{yr}^{-1}\right)$ is the long-term difference of measured precipitation and runoff. The estimation error is calculated as $100\left(E_{\text {est }} / E_{\mathrm{m}}-1\right)$. 
In many cases one would not have access to precipitation records. In such cases one can still perform the above estimation of the mean monthly ET rates with the obvious difference that days when the diurnal rate of change in runoff is positive or zero are considered as 'days with precipitation'. For small watersheds this may not be an unreasonable assumption. Interestingly, such an assumption led to a significant (up to $50 \%$ ) underestimation of the number of days with precipitation in each watershed studied, and, therefore, to a significant overestimation (up to 50\%) of the mean monthly ET values. From this it must follow that there are many days with precipitation when the flow rate remains decreasing for reasons mentioned above and potentially leading to data points that plot under the limiting line in the double-logarithmic graph (Fig. 2).

During the application of Eq. (6) to estimate daily ET for watersheds $\# 3$ and $\# 5$, the $\Delta($.$) value, i.e., the differ-$ ence between the observed and corresponding limitingcase diurnal rate of change values, was replaced by the difference in the observed and the minimum value of the observable diurnal rate of change values for $Q$ 's when the limiting $-\mathrm{d} Q / \mathrm{d} t$ value was significantly smaller than the smallest ever observed $-\mathrm{d} Q / \mathrm{d} t$ value. The reason for this is twofold. Firstly, one does not know the real diurnal rate of change value in such cases due to obvious (the points form horizontal straight lines in the double-logarithmic graph) measurement accuracy limitations. Secondly, when such a gap between measured rate and the limiting line exists in the plot the limiting line may not be valid with these significantly diminished runoff rates when the aquifer is unusually dry and a spatially fully connected saturated zone may not even exist. By not performing any corrections one could grossly overestimate the ET rate (since it is proportional to this $\Delta($.$) difference) for such$ days when the flow rate is small.

Rupp and Selker (2006) suggested a correction when calculating the diurnal rate of change value for small runoff rates. Rather than performing a diurnal difference in the discharge values, they recommend to increase the number of days until the corresponding difference is larger than a critical value $\left(Q_{c r i t}\right)$, a function of measurement accuracy. The rate of change this way becomes this difference divided by the number of days needed to exceed the critical value. The corresponding runoff value is obtained as the mean of the discharge values during this period. The result of such a correction is displayed in Fig. 7 where a critical value $Q_{c r i t}=7 \mathrm{~m}^{3} \mathrm{~d}^{-1}$ was used. In Fig. 2 this is the rate of change value (i.e., $7 \mathrm{~m}^{3} \mathrm{~d}^{-2}$ ) below which the horizontal lines start to form. In the ensuing daily ET estimation for watershed $\# 3$, the newly obtained minimum value (i.e., $1.21 \mathrm{~m}^{3} \mathrm{~d}^{-2}$ ) of Fig. 7 was employed in the $\Delta($.$) differences whenever$ the corresponding limiting line value was less than $1.21 \mathrm{~m}^{3} \mathrm{~d}^{-2}$. The so-estimated mean annual ET of $550 \mathrm{~mm}$ became somewhat closer to the observed $494 \mathrm{~mm} \mathrm{yr}^{-1}$ value, yielding a $10 \%$ difference.

Fig. 8 displays the recession flow data for watershed \#5 in New Hampshire with the above described corrections $\left(Q_{c r i t}=3 \mathrm{~m}^{3} \mathrm{~d}^{-1}\right)$ included. The data points for the assumed limiting case of ET $\approx 0$ form a more diffuse cloud now than for catchment \#3, making the choice of the limiting line more difficult. Fig. 8 has two such lines with equal slopes, the one to the right $\left(-\mathrm{d} Q / \mathrm{d} t=2.46 \times 10^{-5} Q^{2.35}\right)$ is clearly a lower envelope to the densest part of the graph, while the other one $\left(-\mathrm{d} Q / \mathrm{d} t=3.62 \times 10^{-5} Q^{2.35}\right)$ cuts significantly

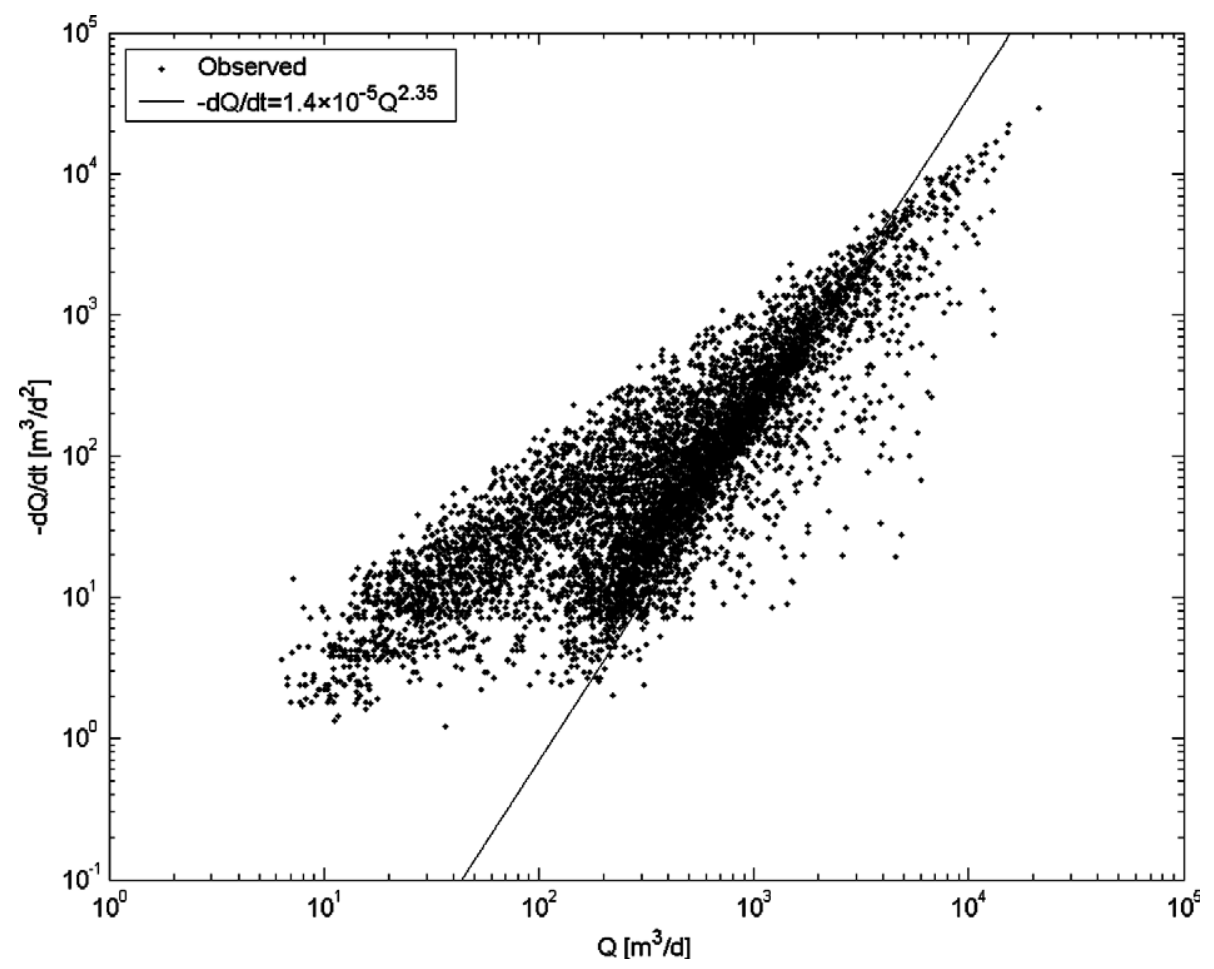

Figure 7 Recession-flow rate versus corrected diurnal rate of change (1958-2004) for watershed \#3, Hubbard Brook Experimental Forest, New Hampshire, US. The straight line shown is the assumed limiting case of ET $=0$. 


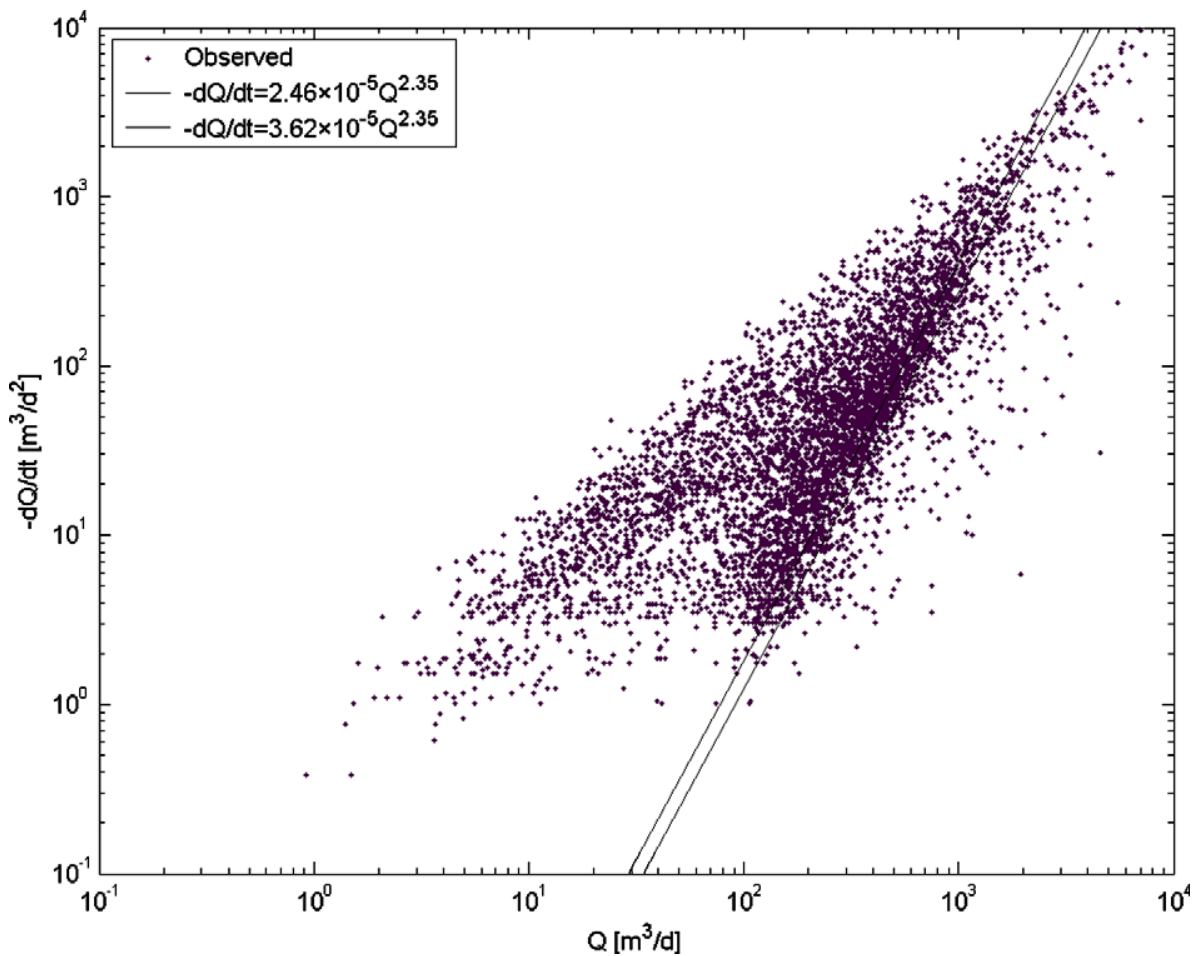

Figure 8 Recession-flow rate versus corrected diurnal rate of change (1964-2004) for watershed \#5, Hubbard Brook Experimental Forest, New Hampshire, US. The straight lines shown are the assumed limiting cases of ET $=0$.

into that cloud. Table 1 lists the ensuing monthly ET estimates. The upper line results in a $21 \%$, while the lower in a $70 \%$ overestimation of the mean annual ET of about $500 \mathrm{~mm}$. Note that the clear cutting down to a trunk diam- eter of $5 \mathrm{~cm}$ did not change this value significantly: it was $505 \mathrm{~mm}$ before 1984, and $495 \mathrm{~mm}$ afterwards.

The corrected Mack Creek, Oregon data is displayed in Fig. 9. Now the limiting line stays all the way close to the

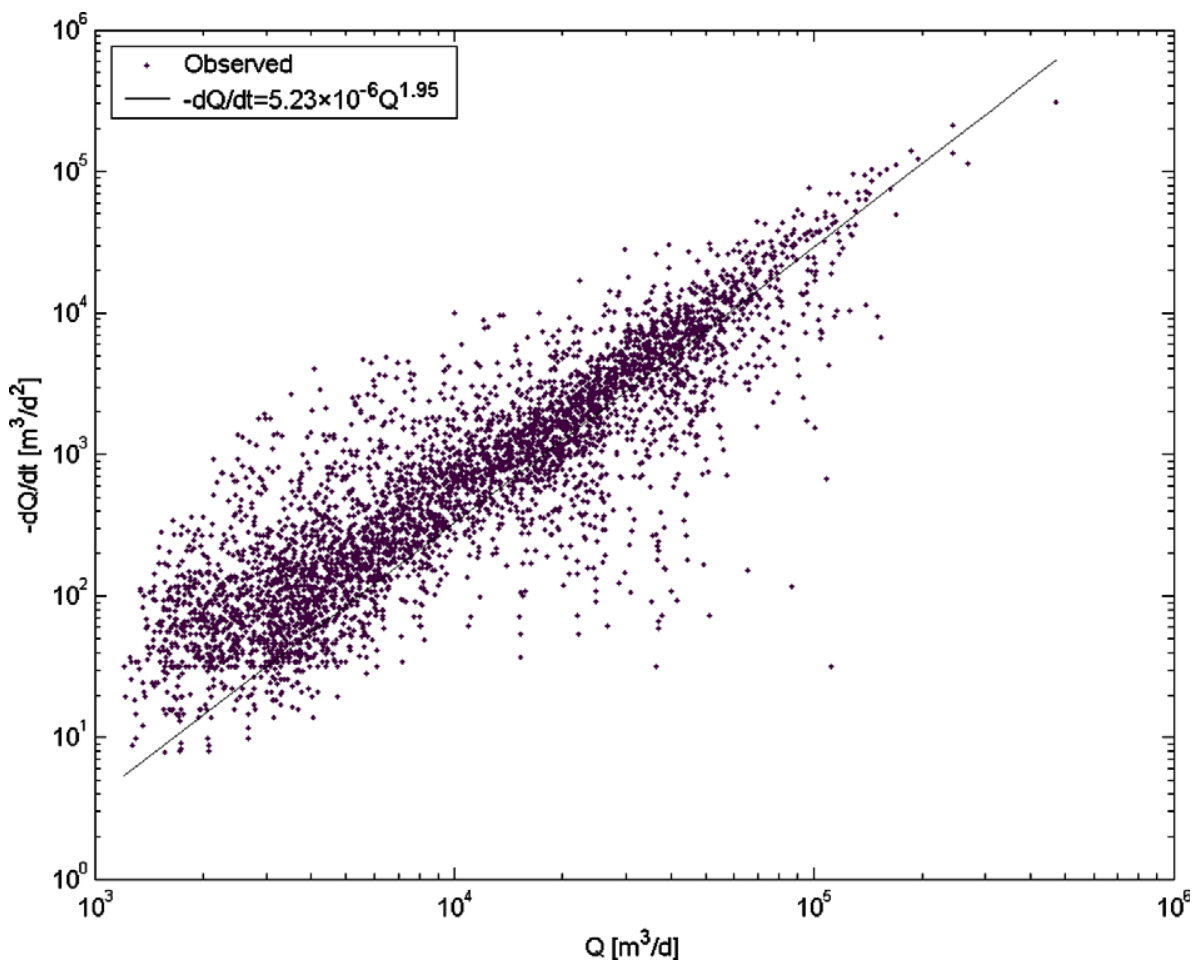

Figure 9 Recession-flow rate versus corrected diurnal rate of change (1979-2004) for Mack Creek, H.J. Andrews Experimental Forest, Oregon, US. The straight line shown is the assumed limiting case of ET $=0$. 


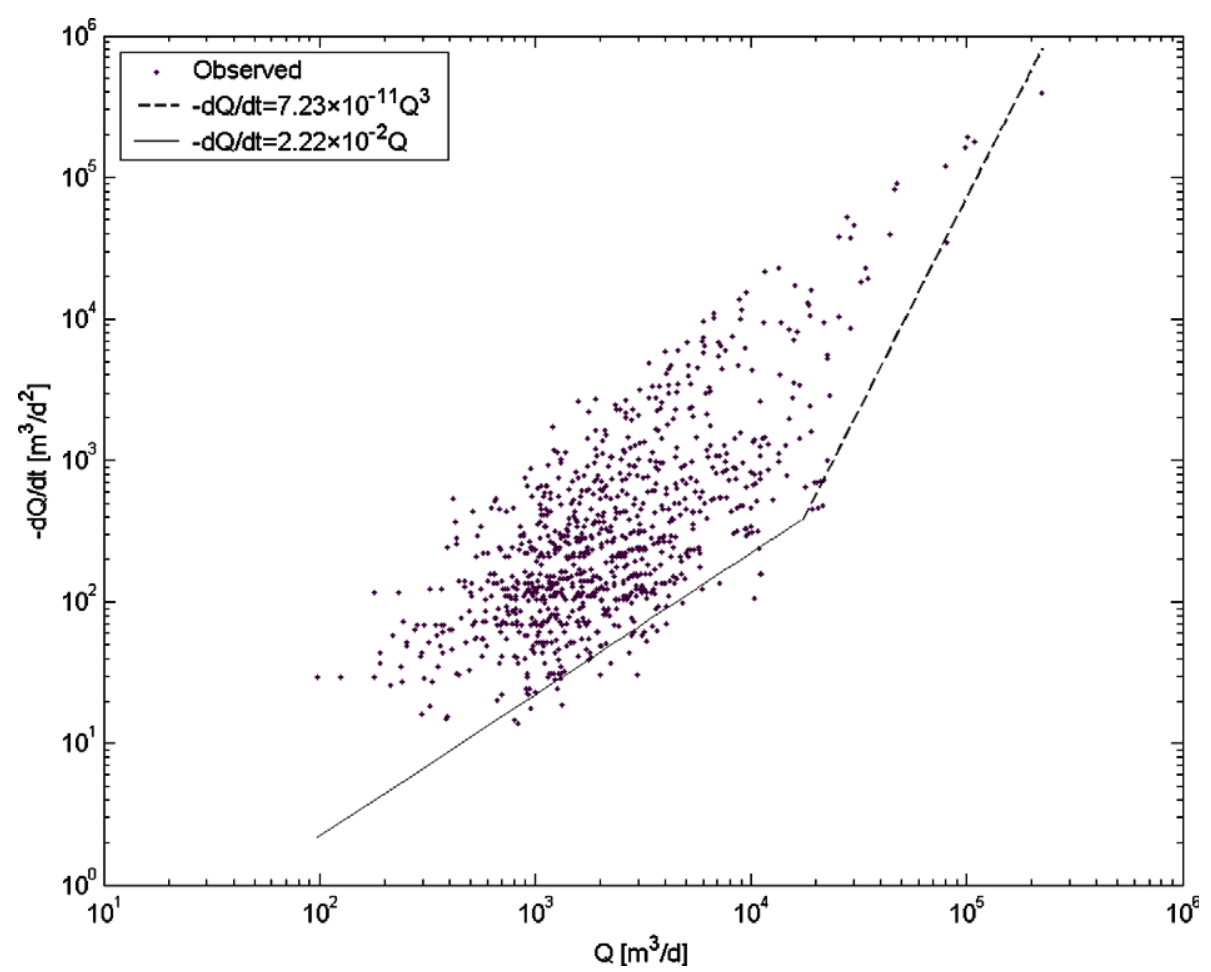

Figure 10 Recession-flow rate versus corrected diurnal rate of change (1967-1977) for catchment \#5141, Washita Experimental Watershed, Oklahoma, US. The straight lines shown are the assumed limiting cases of ET $=0$. Note that the slope values are given by drainage theory (Brutsaert and Lopez, 1998).

derived data points, unlike in the previous cases, thus, a replacement of the limiting line value by the smallest calculated diurnal rate of change was not necessary when calculating daily ET for small runoff values. Table 1 again lists the monthly ET estimates that sum up to $510 \mathrm{~mm}$, a $16 \%$ overestimation of the long-term mean annual ET of $439 \mathrm{~mm}$.

In Fig. 10 the corrected data for catchment \#5141 within the Washita Experimental Watershed is shown. The points now require two lower envelopes as predicted by the hydraulic theory of groundwater drainage (Brutsaert and Nieber, 1977; Brutsaert and Lopez, 1998). During early-time drawdown of negligible ET, the theory predicts that the points in the double-logarithmic graph follow a line of slope 3 which indeed can be detected in Figs. 4 and 5 of the numerical simulation results and yields a well-fitting lower envelope in Fig. 10. For late-time drawdown the theory predicts a slope of unity provided hydrostatic conditions (i.e., Dupuit's theory) prevail, such as can be assumed for catchment \#5141. Note that the two lower envelopes (with assumed slopes of 3 and unity) were fitted independently of the results of Brutsaert and Lopez (1998), yet they almost exactly match their lower envelope equations when the intercept values are brought to the same units. This is all the more interesting because Brutsaert and Lopez (1998) did not perform any correction in the diurnal rate of change calculations. Note that the hydraulic theory referred to here applies only for watersheds with smoothly changing topography where Dupuit's theory holds and it is not valid for the other watersheds studied due to their varied topography and moderate to steep slopes. On these catchments, the data, in accordance with theory, did not necessitate the fitting of lower envelopes with a change in their slopes.
As before, the limiting line for watershed \#5141 stays almost all the way close to the derived data points, therefore, a replacement of the limiting line value by the smallest calculated diurnal rate of change was again sidestepped. Table 1 lists the resulting monthly and annual ET estimates. The estimated mean annual ET rate is very close (within 1\%) to the difference in precipitation and runoff taken for the same period.

\section{Discussion and summary}

As Table 1 illustrates, the mean annual ET estimates can be laden with significant errors. Interestingly, with only one exemption, ET is always overestimated on an annual basis. The most serious problem when applying Eqs. (5) or (6) for practical ET estimation arises from fitting the limiting, $E T=0$, line to the data in the double-logarithmic graph. As was shown in Fig. 8, the placement of the lower envelope of zero ET is always ambiguous with measured data, and a small change in its placing may affect the resulting ET estimates to a potentially great extent. In Fig. 8 an about $40 \%$ increase in the estimated mean annual ET level ensued from a similar, about $40 \%$, decrease in the intercept value. Even in Fig. 10, where the data scatter below the late-time lower envelope drawn is minimal, the placing of the limiting line remains ambiguous. For example employing a lower envelope in Fig. 10 (keeping the unit slope) so that all the data points are above the line results in a 105\% (from 648 to $1330 \mathrm{~mm} \mathrm{yr}^{-1}$ ) increase in estimated mean annual ET. The placement of the zero ET line can, of course, be aided (as was performed in this study) by information of long-term precipitation and runoff. Thus, in one hand, one could place 
the ET $=0$ line so that the estimated mean annual ET would equal the difference in precipitation and runoff for the same period. In the other hand, this line could easily deviate from a reasonable lower envelope of the data points (see e.g., Fig. 8) postulated by the theory. In the ET estimates, summarized in Table 1, a balance was strived to be reached when fitting the lower envelope, i.e., it be a lower envelope to a certain extent at least, yet the ensuing mean annual ET estimates be reasonable as much as possible.

The above approach, however, cannot be used when information of long-term precipitation is missing. Consequently, due to the ambiguous placement of the lower envelope, required by the theory, it may not generally be possible to obtain reliable mean annual watershed-scale ET rates by the sole use of runoff data. One can, however, still argue, that these equations may be used for monthly ET estimations, provided mean annual precipitation and runoff are known to help with placing the lower envelope of zero ET. This possibility is investigated below.

Monthly ET rates were estimated by the WREVAP model (Morton et al., 1985) with data from the Solar and Meteorological Surface Observation Network (SAMSON) at locations (Fig. 1) closest to the study watersheds for the available measurement period of 1961-1990. The WREVAP model is an areal evapotranspiration calculation method that estimates the actual ET rates of the bare or vegetated surface by first determining the so-called wet-environment evaporation as well as the potential evaporation rates. The difference between the two is directly related to the actual ET rate of the area in question. An exhaustive study by Hobbins et al. (2001) recently showed the WREVAP model to be a reliable areal evaporation estimation method, reconfirming Morton et al. (1985).
In Oregon two stations were selected and the estimated monthly ET sum taken as the average of the two values because of the strong humidity gradient across the Cascade Mountains where Mack Creek is situated. Fig. 11 displays the WREVAP-calculated mean monthly ET values together with the estimates of Table 1 . For watershed \#3 the modified values only, while for \#5 the estimates using the upper lower envelope are shown. The WREVAP-model-estimated mean annual ET values based on 11, 27, 30, and 11 years of data (the overlap of the SAMSON and runoff data) for the study watersheds result in the following errors (in the order of Table 1 ): $+6 \%,+5 \%,-6 \%$, and $+12 \%$, respectively, when compared to the long-term mean annual difference in measured precipitation and runoff.

The two estimates differ to a large degree in the mean monthly ET rates for each of the watersheds. If we accept the WREVAP estimates as a more-or-less accurate representation of the annual ET cycle then the Eq. (6)-derived mean monthly values behave spuriously. It is hard to accept an annual maximum of ET in October for the Mack Creek catchment and in November for catchment \#5141 in the Washita basin. Furthermore, none of the runoff-derived ET estimates replicate the assumed annual cycle as displayed by the WREVAP data.

As a summary, the following can be stated. The lumped water balance approach of estimating catchment-scale ET showed great promise with numerical data representing ideal (lack of measurement error, simple geometry and aquifer properties) conditions. The estimates deteriorated with measured data taken from four small watersheds within the US yielding inaccurate ET estimates both on an annual and on a monthly basis. It is believed that a successful application of the method is most significantly (among other
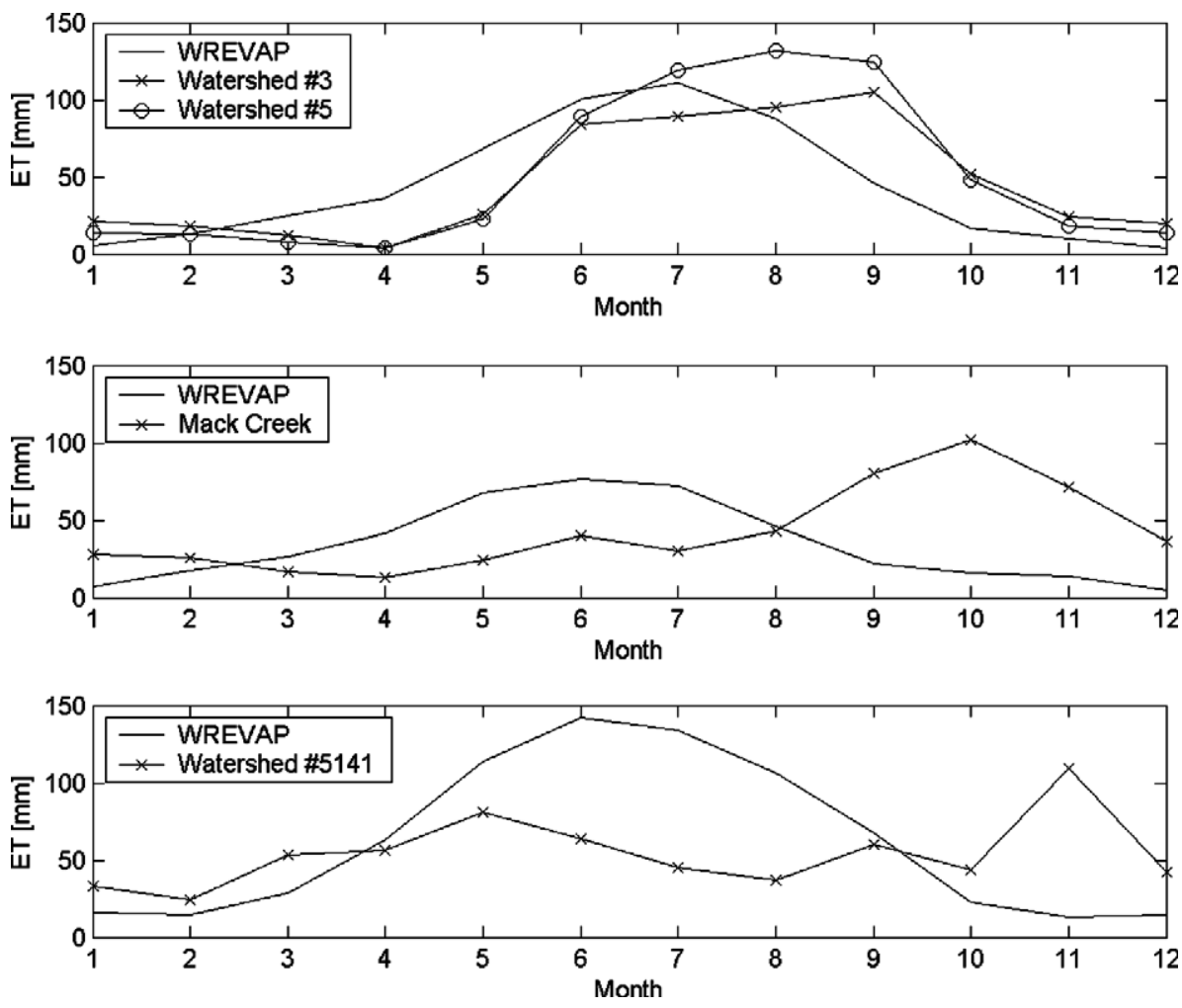

Figure 11 Mean monthly ET estimates by the WREVAP model and by the present approach for the study watersheds. 
possible influences) hindered by the following factors, listed in an order of diminishing importance.

(1) The placing of the lower envelope line, representing zero ET, is always ambiguous because there can be no theoretical limit (the practical limit is the measurement accuracy) to the rate recession flow may decline at any given time. The reason being in the various ways watershed drainage can be influenced. As was mentioned before, if precipitation is light, it will be reported as 'trace' which may end up with a zero value for the day in the final precipitation record or in the modeler's data file. Since these water inputs are small they typically will not reverse the recession trend, rather, they decrease only the rate of change to any possible small value. Other times the precipitation gage may miss the convective and, therefore, greatly localized precipitation events. Even if precipitation is not to be blamed, seasonal (such as snow melting in the spring) or quickly changing physical processes such as the melting of snow during the day (due to insolation) only or the diurnal rhythm of ET provides 'extra' water to the drainage process, the latter during the night when ET is minimal, as was demonstrated by the numerical model in Fig. 5, again leading to a diminished rate of change in runoff. As a side note, this problem of ambiguity in the placing of the lower envelope of the double-logarithmic graph does not surface with the same seriousness when it is applied for aquifer property estimation (Brutsaert and Nieber, 1977; Brutsaert and Lopez, 1998 ) because then a potential $50 \%$ error is still negligible to the possible range of the parameter values (e.g., it is of 13 magnitudes for the saturated hydraulic conductivity and at least of one magnitude for drainable porosity).

(2) The present approach can yield ET estimates only during recession flow conditions of no precipitation, therefore, when monthly or annual sums are needed, the number of precipitation days is also needed for the calculations because on those days ET may significantly be smaller than during drought-flow days. Not (or incorrectly) accounting for these days with precipitation can lead to overestimation of the monthly or annual ET sums. This requirement may reduce the attractiveness of the present approach where, in theory, one needs to have access to the flow record only, which is typically abundant and goes back a century in many cases.

(3) The method cannot account for evaporation of water intercepted by the vegetation. Interception losses in forested watersheds (three out of the four catchments investigated here) may account for $10-30 \%$ of gross precipitation on an annual basis (Dunne and Leopold, 1978). Therefore, the annual ET rate can be expected to be underestimated by this amount when employing the present method, even under ideal conditions. This deficit did not show up in the present study (Table 1) due to (a) neglecting interception in the numerical experiment, and; (b) the deliberate placement of the lower envelope line mentioned above for the watershed data.
(4) The effect of flowrate measurement error to the ensuing ET estimation accuracy is hard to quantify. Employing the method of Rupp and Selker (2006) allows one to reduce this effect, as was demonstrated for watershed \#3.

(5) Finally, there may be other unknown causes that eventually lead to inaccurate monthly and annual ET estimations with the present method, at least when compared with the WREVAP-model estimates, for the watersheds studied.

\section{Disclaimer}

The views, conclusions and opinions expressed in this paper are solely those of the authors and not the University of $\mathrm{Ne}$ braska, state of Nebraska or any political subdivision thereof.

\section{Acknowledgments}

Some data used in this publication was obtained by scientists of the Hubbard Brook Ecosystem Study; this publication has not been reviewed by those scientists. The Hubbard Brook Experimental Forest is operated and maintained by the Northeastern Research Station, US Department of Agriculture, Newton Square, Pennsylvania.

The H.J. Andrews Experimental Forest data sets were provided by the Forest Science Data Bank, a partnership between the Department of Forest Science, Oregon State University, and the US Forest Service Pacific Northwest Research Station, Corvallis, Oregon. Significant funding for these data was provided by the National Science Foundation Long-Term Ecological Research program (DEB-02-18088).

The Washita watershed data were made available by the Agricultural Research Service of the US Department of Agriculture.

The authors are grateful for the anonymous reviewers whose comments substantially improved the manuscript.

\section{References}

Brutsaert, W., 1982. Evaporation into the Atmosphere: Theory, History, and Applications. Kluwer Academic, Dordrecht.

Brutsaert, W., Nieber, J.L., 1977. Regionalized drought flow hydrographs from a mature glaciated plateau. Water Resour. Res. 13, 637-643.

Brutsaert, W., Lopez, J.P., 1998. Basin-scale geohydrologic drought flow features of riparian aquifers in the southern Great Plains. Water Resour. Res. 34 (2), 233-240.

Chow, V.T. (Ed.), 1964. Runoff. Handbook of Applied Hydrology. McGraw-Hill, New York.

Crawford, N.H., Linsley, R.K., 1966. Digital simulation in hydrology: Stanford watershed model 4. Technical Report 39, Department of Civil Engineering, Stanford University, Stanford, CA.

Daniel, J.F., 1976. Estimating groundwater evapotranspiration from streamflow records. Water Resour. Res. 12, 360-364.

Dunne, T., Leopold, L.B., 1978. Water in Environmental Planning. W.H. Freeman, New York.

Federer, C.A., 1973. Forest transpiration greatly speeds streamflow recession. Water Resour. Res. 9 (6), 1599-1604.

Hobbins, M.T., Ramirez, J.A., Brown, T.C., Claessens, L.H.J.M., 2001. The complementary relationship in estimation of regional 
evapotranspiration: The complementary relationship areal evapotranspiration and advection-aridity models. Water Resour. Res. 37 (5), 1367-1387.

Holtan, H.N., Lopez, N.C., 1971. USDAHL-70 model of watershed hydrology. US Dept. Agr. Tech. Bull. 1435, 1-84.

Lam, L., Fredlund, D.G., Barbour, S.L., 1987. Transient seepage model for saturated-unsaturated soil systems: A geotechnical engineering approach. Can. Geotech. J. 24, 565-580.

McMahon, T.A., Finlayson, B.L., 2003. Droughts and anti-droughts: the low flow hydrology of Australian rivers. Freshwater Biol. 48, $1147-1160$.

Morton, F.I., Ricard, F., Fogarasi, F., 1985. Operational estimates of areal evapotranspiration and lake evaporation - Program
WREVAP. NHRI Paper 24, National Hydrologic Research Institute, Saskatoon, Canada.

Rupp, D.E., Selker, J.S., 2006. Information, artifacts, and noise in $\mathrm{dQ} / \mathrm{d} t-\mathrm{Q}$ recession analysis. Adv. Water Resour. 29 (2), 154160.

Singh, K.P., Stall, J.B., 1971. Derivation of base flow recession curves and parameters. Water Resour. Res. 7 (2), 292-303.

Szilagyi, J., 2003. Sensitivity analysis of aquifer parameter estimations based on the Laplace equation with linearized boundary conditions. Water Resour. Res. 39 (6), \#1156.

Tschinkel, H.M., 1963. Short-term fluctuation in streamflow as related to evaporation and transpiration. J. Geophys. Res. 68, 6459-6469. 